\title{
PENGEMBANGAN SUMBER BELAJAR GEOGRAFI BERBASIS WEBLOG PADA MATERI PELAJARAN GEOGRAFI KELAS XII DI SMA PEMBANGUNAN LABORATORIUM UNP
}

\author{
Abdul Aziz Asra ${ }^{1}$ dan Nofrion ${ }^{2}$ \\ Program Studi Pendidikan Geografi \\ Fakultas Ilmu Sosial, Universitas Negeri Padang \\ Email: abdulazizasra06@gmail.com
}

\begin{abstract}
Abstrak
Penelitian ini bertujuan untuk mengembangkan sumber belajar geografi berbasis weblog yang valid dan praktis. Jenis penelitian ini adalah penelitian pengembangan dengan mengadaptasi model ASSURE yang disesuaikan dengan Level 6 KKNI . Model dikembangkan dalam enam tahapan yaitu (1) analisis peserta didik, (2) merumuskan tujuan pembelajaran, (3) memilih metode, media dan bahan ajar, (4) memanfaatkan media dan materi, (5) mengembangkan peran serta peserta didik, (6) evaluasi dan revisi. Validasi dilakukan oleh ahli perangkat pembelajaran, ahli materi dan media. Kepraktisan dilakukan oleh dua orang Guru Geografi dan 34 orang siswa SMA Pembangunan Laboratorium UNP. Hasil penelitian menunjukan bahwa sumber belajar geografi berbasis weblog sangat valid dan sangat praktis. Ahli perangkat pembelajaran menilai sangat valid dengan nilai akhir $87,03 \%$, ahli materi $88,27 \%$, dan ahli media 88,54\%. Guru geografi menilai sangat praktis dengan nilai akhir $99,10 \%$, dan siswa kelas XII IPS 1 menilai sangat praktis dengan nilai akhir $86,76 \%$.
\end{abstract}

Kata Kunci: Pembelajaran Geografi, Sumber Belajar Geografi, Weblog Geografi.

\begin{abstract}
Abstrack
The research is conducted in order to develope the valid and practical Geography learning resource weblog. This research was research and development by adapting the ASSURE model. This mode can be increase in the 6 stages: (1) analyze learners, (2) state objectives, (3) select methods, media and materials, (4) utilize materials, (5) require learners participation, (6) evaluated and revise. Validation is done by the learning device expert, the matter and media expert. practicality has been done by 2 geography teachers and 34 students of SMA Pembangunan Laboratorium UNP. The results show that the source of weblog based learning weblog is very valid and very practicability. Expert learning tool rate is very valid with final score 87,03\%, matter expert $88,27 \%$, and media expert $88,54 \%$. The geography teacher rate is very practicability with a final grade of $99,10 \%$, and the student class XII IPS 1 rate is very practicability with a final value of $86.76 \%$.
\end{abstract}

Keywords: Geography Learning , Geography Learning Resources, Weblog Geography

\footnotetext{
${ }^{1}$ Mahasiswa Program Studi Pendidikan Geografi untuk wisuda Maret 2018

${ }^{2}$ Dosen Jurusan Geografi Fakultas Ilmu Sosial Universitas Negeri Padang, pembimbing I Nofrion, M.Pd,
} 


\section{PENDAHULUAN}

Pembelajaran adalah hubungan interaksi antara peserta didik dengan guru dan sumber belajar pada suatu lingkungan belajar. Pembelajaran harus diadakan secara interaktif, isnpiratif, menyenangkan, menantang dan memotivasi siswa untuk mengembangkan potensi, kreativitas dan kemandiriannya (Nofrion 2017: 163). Proses pembelajaran pada saat sekarang ini cendrung hanya terfokus pada guru, guru hanya memberi informasi (proses satu arah) tanpa ada umpan balik, maka lingkungan dan proses pembelajran hanyalah terpusat pada guru, sementara siswa tidak terlibat aktif dalam pembelajaran. Pembelajaran yang efektif adalah pembelajaran yang tidak hanya fokus pada kemampuan kognitif saja, namun juga memberikan ruang untuk terciptanya saling peduli dan kolaborasi antar peserta didik (Nofrion 2017: 19)

Karakteristik mata pelajaran Geografi, merupakan salah satu mata pelajaran yang dominan dengan aspek kognitif atau pengetahuan dan aspek afektif, sedangkan aspek praktik atau psikomotor sifatnya hanya menunjang proses pembelajaran. Arti Geografi yang sebenarnya adalah uraian (grafien artinya menguraikan atau melukiskan) tentang bumi (geos) dengan segenap isinya, yakni manusia, yang kemudian ditambah lagi dengan dunia hewan dan dunia tumbuhan. Menurut Sumaatmadja (1988:31) bahwa geografi adalah ilmu dengan kajian meliputi segala gejala yang terdapat di muka bumi, baik sosial maupun fisiknya yang berkaitan dengan kehidupan manusia. Kenyataan ini mengharuskan siswa bekerja keras dengan menggunakan strategi khusus untuk mempelajarinya dan membutuhkan sumber yang efektif dan terpercaya.

Pada pembelajaran geografi dibutuhkan interaksi antara pendidik dengan peserta didik dan sumber belajar, baik secara langsung (tatap muka) ataupun tidak langsung (menggunakan sumber belajar atau media pembelajaran) yang berisikan serangkaian peristiwa yang dirancang, disusun untuk mempengaruhi dan mendukung terjadinya proses belajar yang membahas tentang aspek dan fenomena geografi yang ada pada suatu lingkungan. Sumber belajar pada dasarnya banyak sekali baik yang terdapat di lingkungan kelas, sekolah, sekitar sekolah bahkan di masyarakat, keluarga, di pasar, kota, desa, hutan, internet dan sebagainya, yang perlu dipahami dalam hal ini adalah masalah pemanfaatannya yang akan tergantung kepada kreativitas dan budaya mengajar guru atau pendidikan itu sendiri. Kenneth Silber (dalam warsita, 2008:211) mengemukakan bahwa sumber belajar meliputi semua sumber yang berkenaan dengan data, manusia, barang-barang yang memungkinkan dapat digunakan secara terpisah atau kombinasi, yang oleh peserta didik biasanya digunakan secara optimal untuk memberikan fasilitas dalam kegiatan belajar.

Sumber belajar merupakan salah satu elemen penting dalam pembelajaran karena sumber belajar adalah pemicu terjadinya interaksi antara pendidik dengan peserta didk 
serta pesesrta didik dengan peserta didik yang lain dalam suatu lingkungan belajar. Penyediaan dan penataan sumber belajar yang valid dan "up date" serta sesuai dengan perkembangan ilmu pengetahuan dan teknologi adalah cara jitu untuk meningkatkan kualitas pembelajaran.

Jika dalam konteks pendidikan tradisional guru adalah sumber belajar utama maka, dalam kurikulum 2013, peran guru sudah menjadi salah satu sumber belajar, dari pemberi tahu menjadi pemicu anak untuk mencari tahu serta dari "teacher dominated learning" menjadi fasilitator "learning observatory". Namun demikian berjalannya pembelajaran tetap berada dalam kendali dan pengelolaan guru. Tugas utama guru adalah menumbuhkan kesadaran dan kepedulian belajar di kalangan peserta didik serta merangsang peserta didik untuk belajar optimal (Nofrion 2017: 12).

Maka ditengah pesatnya perkembangan teknologi informasi dan komunikasi, guru bukanlah satu-satunya sumber belajar yang dimiliki siswa, siswa sudah bisa mengakses internet secara mudah dan cepat. Keberadaan teknologi informasi/internet, akan menambah tekanan yang ada menjadi tekanan dan tantangan yang sangat luar biasa di dunia pendidikan (Uno dan Nina 2011:7).

Jika selama ini, buku menjadi sumber belajar utama maka saat ini buku telah mengalami perkembangan menjadi buku-buku online yang bisa diakses oleh siapapun kapanpun dan dimanapun. Apalagi saat ini, peserta didik dan sekolah sudah dapat mengakses semua konten online melalui internet melalui laptop maupun gadget/smartphone masing-masing. Sumber belajar online dirasakan lebih efektif dan efisien dibanding sumber belajar berbentuk fisik. Banyak kemudahan-kemudahan yang didapatkan dari sumber belajar online. Diantaranya adalah dapat diakses kapanpun dan dimanapun, tidak memerlukan ruang atau tempat, tidak membutuhkan energi atau tenaga atau wadah khusus untuk membawanya serta dapat dipelajari atau ditampilkan dalam berbagai situasi baik secara mandiri atau berkelompok bahkan klasikal.

Salah satu hal yang menarik dari internet ialah weblog atau biasa disebut blog. Blog awalnya hanya berupa situs pribadi yang memuat kumpulan link situs favorit pemiliknya dan cenderung hanya sebagai tempat diary online saja. Namun seiring popularitas dan daya tariknya kini blog sudah berkembang menjadi suatu sumber berita atau informasi alternatif. Blog merupakan media yang dapat digunakan secara personal, baik individual maupun institusional. Blog dapat dibuat oleh semua orang. Tidak diperlukan kemampuan teknis atau kemampuan dasar jurnalisme untuk mempublikasikan informasi dalam blog.

Blog dapat dipahami sebagai sebuah tipe atau bentuk website yang biasanya disusun secara teratur dan kronologis, dengan susunan entri atau posting paling baru pada pengaturan paling atas dari halaman pertama, dan selanjutnya berurutan ke entri atau posting sebelumnya (Kindarto, 2006:2). 
Blog merupakan salah satu bentuk aplikasi yang dapat digunakan oleh pendidik dan pelajar sebagai sumber belajar yang tidak terbatas.

Berdasarkan wawancara awal yang peneliti lakukan dengan guru mata pelajaran Geografi di SMA Pembangunan Laboratorium UNP, diketahui siswa cenderung kurang menyukai pelajaran Geografi sehingga proses pembelajaran cenderung berjalan satu arah, siswa lebih asyik bermain HP secara sembunyi-sembunyi dibandingkan mendengarkan penjelasan guru, apalagi SMA Pembangunan Laboratorium UNP menyediakan WI-FI gratis bagi siswa sehingga siswa dengan mudah mengakses internet di lokal. Fenomena tersebut disebabkan oleh banyak faktor, diantaranya metode yang cenderung digunakan adalah metode ceramah yang hanya menjelaskan konsep, yang tidak terlalu melibatkan siswa atau kurang berinteraksinya antara guru dengan siswa selama proses pembelajaran, media pembelajaran guru yang masih apa adanya, dan ditambah lagi sumber belajar Geografi itu sendiri yang masih kurang dikalangan para guru.

Berdasarkan fenomena tersebut, perlu adanya suatu tindakan perbaikan pada proses pembelajaran mata pelajaran Geografi, agar permasalahan tersebut dapat diminimalkan sehingga tujuan pembelajaran dapat tercapai. Untuk memperbaiki kondisi-kondisi terutama berpangkal kepada kurangnya aktivitas belajar siswa dan media pembelajaran guru yang masih kurang, maka perlu dicari solusi pemecahan masalah agar pembelajaran lebih efektif. Salah satu alternatif pemecahan masalah-masalah ini adalah dengan menerapkan strategi pembelajaran berbasis Weblog dalam mata pelajaran Geografi di SMA Pembangunan Laboratorium UNP.

Sumber belajar geografi berbasis weblog dapat memberikan kemudahan dalam interaksi guru dan peserta didik dalam pembelajaran. Tampilan yang menarik yang didukung gambar dapat meningkatkan daya pikir anak dalam menganalis fenomena yang ditampilkan, bahan ajar yang lengkap dapat menambah wawasan peserta didik dalam pembelajaran geografi, siswa dapat melatih pengetahuan Geografi dengan adanya soal evaluasi.

Berdasarkan uraian tersebut, peneliti tertarik untuk mengadakan sebuah penelitan dengan judul "Pengembangan Sumber Belajar Geografi Berbasis Weblog Pada Materi Pembelajaran Geografi Kelas XII di SMA Pembangunan Laboratorium UNP”

\section{METODOLOGI PENELITIAN}

Jenis penelitian yang akan dilakukan adalah penelitian pengembangan (Research and Development) atau disingkat dengan R\&D. Penelitian ini sesuai dengan level Kerangka Kualifikasi Nasional Indonesia (KKNI), maka pengembangan yang dilakukan dibatasi pada level S1 yaitu pada level 6 KKNI yaitu mengaplikasikan, mengkaji, membuat desain, memanfaatkan IPTEK, dan menyelesaikan masalah. Menurut Sugiyono

(2012:407) 
penelitian pengembangan adalah metode penelitian yang digunakan untuk menghasilkan produk tertentu, dan menguji keefektifan produk tersebut.

Objek penelitian adalah sumber belajar Geografi berbasis weblog. Sumber belajar yang dikembangkan berisi materi Geografi pada semester satu dan dua Kelas XII SMA.

Subjek uji coba dalam penelitian ini adalah 2 orang guru mata pelajaran geografi kelas XII SMA Pembangunan Laboratorium UNP dan 34 orang siswa kelas XII IPS 1 SMA Pembangunan Laboratorium UNP.

Jenis Data pada penelitian ini adalah data kualitatif dan data kuantitatif. Data kualitatif diperoleh dari hasil pengamatan, sedangkan data kuantitatif diperoleh dari hasil angket lembar validasi dan lembar praktikalitas.

Prosedur Pengembangan Berdasarkan model pengembangan ASSURE, maka prosedur penelitian pengembangan sumber belajar geografi berbasis Weblog ini akan mengikuti langkah-langkah yang diinstruksikan dalam model tersebut. Langkah pengembanganya yaitu 1) Analyze Learners (analisis karakteristik siswa), 2) State Standars and Objective (merumuskan tujuan pembelajaran), 3) Select Methods, Media, and Materials (memilih metode, media, dan bahan ajar), 4) Utilize Materials (memanfaatkan material), 5) Requires Learner Participation (mengembangkan peran serta peserta didik), 6) Evaluate and Revise (mengevaluasi dan revisi)
Instrumen Pengumpulan Data yang digunakan dalam penelitian ini adalah angket validitas dan angket kepraktisan.

Teknik Analisis Data yang digunakan adalah analisis validitas produk weblog dan kepraktisan weblog yang dikembangkan.

Analisis Validitas Sumber Belajar Geografi Berbasis Weblog berdasarkan angket yang telah diisi oleh tenaga ahli dan praktisi dianalisis untuk mengetahui tingkat kevalidan dari produk yang dikembangkan. Analisis validitas menggunakan Skala Likert dilakukan dengan langkah-langkah:

a. Memberikan skor untuk setiap item jawaban sangat setuju (4), setuju (3), tidak setuju (2), sangat tidak setuju (1).

b. Menjumlahkan skor total tiap validator untuk seluruh indikator.

c. Pemberian nilai validitas dengan cara menggunakan rumus:

$$
P=\frac{f}{N} \times 100 \%
$$

Dimana:

$\mathrm{P}=$ Nilai akhir

$f=$ Perolehan skor

$\mathrm{N}=$ Skor maksimum

Kategori validitas dapat dilihat pada Tabel 1

Tabel 1. Kategori Validitas

\begin{tabular}{|c|l|l|}
\hline No & \multicolumn{1}{|c|}{ Nilai } & \multicolumn{1}{|c|}{ Kriteria } \\
\hline 1 & $\begin{array}{l}80 \%<\mathrm{x} \leq \\
100 \%\end{array}$ & Sangat valid \\
\hline 2 & $60 \%<\mathrm{x} \leq 80 \%$ & Valid \\
\hline 3 & $40 \%<\mathrm{x} \leq 60 \%$ & Cukup valid \\
\hline 4 & $20 \%<\mathrm{x} \leq 40 \%$ & Kurang valid \\
\hline 5 & $0 \%<\mathrm{x} \leq 20 \%$ & Tidak valid \\
\hline
\end{tabular}

Dimodifikasi dari Riduwan (2009)

Teknik Analisis praktikalitas sumber belajar berbasis weblog dalam 
pembelajaran Geografi berdasarkan angket dengan langkah-langkah berikut ini:

a. Memberikan skor untuk setiap item jawaban sangat setuju (4), setuju (3), tidak setuju (2) dan sangat tidak setuju (1).

b. Menjumlahkan skor total tiap validator untuk seluruh indikator.

c. Pemberian nilai validitas dengan cara menggunakan rumus:

$$
P=\frac{f}{N} \times 100 \%
$$

dimana:

$\mathrm{P}=$ Nilai akhir

$f=$ Perolehan skor

$\mathrm{N}=$ Skor maksimum

Kategori praktikalitas dapat dilihat pada Tabel 2.

Tabel 2. Kategori Kepraktisan

\begin{tabular}{|c|l|l|}
\hline No & \multicolumn{1}{|c|}{ Nilai } & \multicolumn{1}{c|}{ Kriteria } \\
\hline 1 & $80 \%<\mathrm{x} \leq 100 \%$ & Sangat praktis \\
\hline 2 & $60 \%<\mathrm{x} \leq 80 \%$ & Praktis \\
\hline 3 & $40 \%<\mathrm{x} \leq 60 \%$ & Cukup praktis \\
\hline 4 & $20 \%<\mathrm{x} \leq 40 \%$ & Kurang praktis \\
\hline 5 & $0 \%<\mathrm{x} \leq 20 \%$ & Tidak praktis \\
\hline
\end{tabular}

Dimodifikasi dari Riduwan (2009)

\section{HASIL DAN PEMBAHASAN}

Hasil yang diperoleh dari penelitian ini terdiri dari tiga komponen. Ketiga komponen ini proses pengembangan sumber belajar berbasis weblog dengan model pengembangan ASSURE, validitas sumber belajar, dan praktikalitas sumber belajar berbasis weblog.

\section{Tahapan Prosedur Pengembangan Penelitian}

Pengembanagan sumber belajar Geografi berbasis weblog pada materi pembelajaran Geografi kelas XII SMA ini melalui enam tahapan sesuai dengan prosedur pengembangan ASSURE

Tahap pertama adalah Analyze Learners (Analisis Peserta Didik) dilakukan dengan dua cara, pertama melihat karakterisitik umum dan karakterisitik khusus peserta didik. Karakterisitik umum peserta didik di SMA Pembangunan Laboratorium UNP hampir seluruh pelajar di SMA Pembangunan Laboratorium UNP memiliki HP atau smartphone. Pelajar yang memiliki smartphone selalu membawa barang tersebut ke sekolah, tidak jarang mereka menggunakannya saat jam pelajaran. Penggunaan smartphone untuk menghitung, internet, bahkan untuk bermain game dan membuka jejaring sosial seperti facebook, twitter ataupun instagram sering dilakukan pelajar ketika proses belajar mengajar sedang berlangsung. SMA Pembangunan Laboratorium UNP juga memberikan fasilitas berupa Wi-fi gratis pada setiap siswa.

Analisis karakterisitik spesifik siswa kelas XII SMA Pembangunan Laboratorium UNP yaitu rata-rata nilai ulangan harian siswa kelas XII IPS 1 tergolong rendah dibandingkan dengan tiga kelas yang lainnya yaitu 73,25 sedangkan kelas XII IPS 2 mempunyai rata-rata nilai 78,47 kelas XII IPS 3 mempunyai rata-rata 75,83 dan yang terakhir kelas XII IPS 4 mempunyai rata-rata 82,86 dimana syarat ketuntasan dari mata pelajaran Geografi di SMA Pembangunan Laboratorium UNP tergolong tinggi yaitu dengan nilai 81 
Tahap kedua State Objective (Merumuskan Tujuan Pembelajaran. Tujuan umum dari pengembangan sumber belajar geogafi berbasis blog ini adalah memfasilitasi peserta didik yang akrab dengan laptop dan smartphone supaya fasilitas yng diberikan orang tua dan sekolah dapat dimanfaatkan secara optimal.

Pada tahap ini peneliti merumuskan tujuan khusus pengembangan sumber belajar berbasis blog dengan mengacu pada silabus kurikulum 2013 revisi mata pelajaran Geografi Kelas XII.

Tahap ketiga adalah Select Intructional Methods, Media and Materials (Memilih Metode, Media, dan Bahan Ajar). Metode yang digunakan adalah metode demonstrasi. Media blog digunakan sebagai sumber belajar siswa, karena pemahaman siswa terhadap internet yang baik memudahkan siswa mendapatkan sumber belajar geografi melalui pengaplikasian smartphone siswa. Materi yang dipilih berupa keseluruhan materi kelas XII SMA yang dikembangkan dalam bentuk Silabus, RPP, Bahan Ajar, LKPD, dan PPT. Penyusunan sumber belajar tersebut telah disesuaikan dengan kebutuhan guru dan siswa berdasarkan kurikulum 2013 revisi. langkah-langkah pengembangannya sebagai berikut:

1. Menganalisis KI dan KD dari silabus kurikulum 2013 revisi mata pelajaran geografi tingkat SMA

2. Menyususn RPP sesuai dengan KI dan KD dari silabus
3. Mengumpulkan bahan ajar dari dari buku teks geografi, modul dan internet. Setelah terkumpul lalu disusun berdasarkan KI, KD dan Indikator sesuai RPP

4. Membuat PPT sesuai dengan bahan ajar

5. Menyusun LKPD sesuai dengan tujuan pembelajaran dan KI 4

Setelah mengembangkan materi geografi kelas XII SMA berupa Silabus, RPP, Bahan Ajar, LKPD dan PPT, tahap selanjutnya adalah melakukan validasi terhadap RPP, Bahan Ajar dan PPT.

Tahap keempat adalah Utilize Media and Materials (Memanfaatkan Media dan Materi). Setelah dilaksanakannya validasi perangkat pembelajaran dan materi oleh ahli perangkat dan ahli materi, Sumber belajar geografi kelas XII SMA diupload kedalam sebuah blog yang bertujuan agar guru dan peserta didik mudah mengaksesnya. Teknologi pendukung lainnya yaitu berupa komputer/laptop, dan smartphone yang dapat terhubung ke internet. Selanjutnya sumber belajar tersebut diupload kedalam blog yang didesain menarik dan mudah diaplikasikan baik dikomputer/laptop dan smartphone. Penilaian dari ahli media juga diperlukan untuk menguji atau memberikan penilaian terhadap komponen blog.

Tahap kelima adalah Require Learner Participation (Mengembangkan Peran Serta Pesrta Didik. Keterlibatan siswa diperlukan untuk penggunaan sumber belajar 
geografi berbasis weblog. Pada tahap ini siswa akan diminta untuk belajar menggunakan sumber belajar weblog yang telah disediakan. Dalam melihat partisipasi peserta didik dapat dilakukan uji coba lapangan dikelas. Uji coba produk dilakukan di kelas XII IPS 1 SMA Pembangunan Laboratorium UNP yang berjumlah 34 orang siswa. Smartphone tersebut digunakan saat proses belajar mengajar mata pelajaran dilakukan seperti biasa didalam kelas dengan bantuan sumber belajar geografi berbasis blog dengan cara mengakses http://sumberbelajargeografisma.blogsp ot.co.id melalui jaringan wifi yang disediakan sekolah peserta didik juga dapat mengunduh sumber belajar yang telah diunggah pada halaman weblog. Tampilan halaman beranda weblog sumber belajar Geografi SMA kelas XII dapat dilihat pada gambar 1 berikut: geografi. Setelah itu pembelajaran

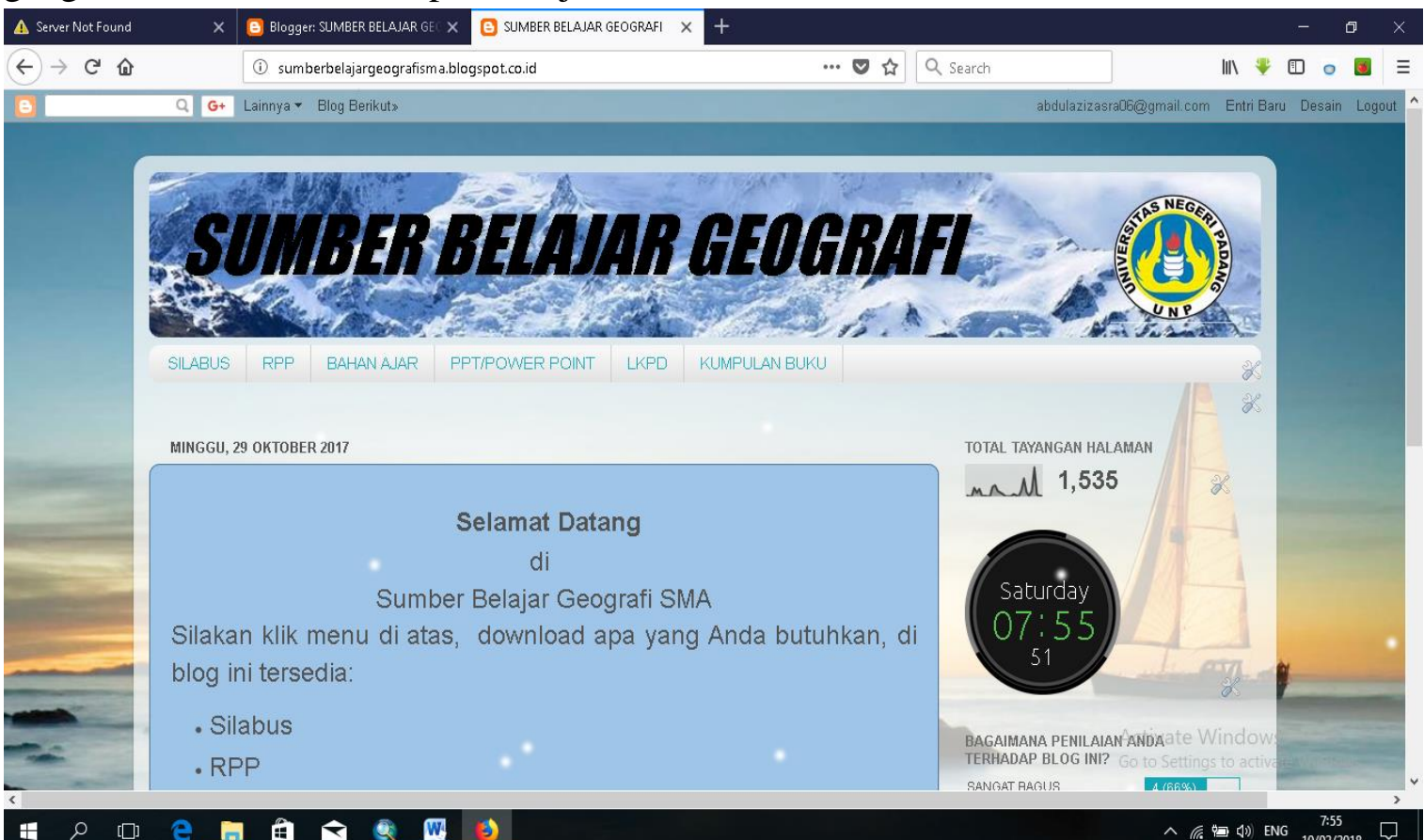

Gambar1. Tampilan Beranda Sumber Belajar Geografi Berbasis Weblog Sumber. Sumberbelajargeografisma.blogspot.co.id

Setelah siswa mencoba belajar menggunakan sumber belajar geografi berbasis weblog tersebut, siswa diminta mengisi angket yang diberikan untuk mengutarakan penilaian dan pendapat/saran terhadap weblog geografi. Tujuan dari penilaian ini untuk mengetahui kepraktisan sumber belajar berbasis weblog terkait aspek kemudahan penggunaan, efesiensi waktu dan manfaat dari blog.
Tahap keenam adalah Evaluate and Revise (Evaluasi dan Revisi). Setelah melibatkan siswa dan guru selanjutnya diadakan evaluasi dan revisi terhadap sumber belajar berbasis weblog, tahap ini bertujuan untuk menilai layak atau tidaknya sebuah produk yang dikembangkan. Penilaian dan perbaikan atau revisi adalah aspek yang sangat penting untuk mengembangakan kualitas dari produk 
sumber belajar berbasis weblog. Penilaiaan dan revisi yang dilakukan dalam suatu pembelajaran menyangkut dengan teknologi dan media yang digunakan. Salah satu komponen kunci evaluasi dan revisi terhadap suatu teknologi dan media yang digunakan adalah masukan dari guru dan siswa

\section{Analisis Data Validitas}

Analisis data merupakan bagian yang menyajikan hasil analisis dari data yang diperoleh pada saat melakukan langkah-langkah penelitian pengembangan. Validitas sumber belajar geografi berbasis weblog dilihat dari: (a) perangkat pembelajaran, (b) materi, dan (c) media.

\section{a. Analisis Data Validasi Perangkat Pembelajaran}

Hasil analisis data validasi ahli perangkat pembelajaran adalah sebagai berikut:

Tabel 3. Hasil Penilaian Ahli

Perangkat Pembelajaran (RPP)

\begin{tabular}{|c|c|c|}
\hline Aspek & $\begin{array}{c}\text { Nilai } \\
\text { Akhir }\end{array}$ & Kriteria \\
\hline Kelayakan Isi & $75 \%$ & Valid \\
\hline Kebahasaan & $87,5 \%$ & Sangat valid \\
\hline Penyajian & $95,83 \%$ & Sangat valid \\
\hline Kegrafikan & $75 \%$ & Valid \\
\hline Jumlah & $\mathbf{8 7 , 0 3 \%}$ & Sangat valid \\
\hline
\end{tabular}

Sumber : Olahan Data Primer

Berdasarkan tabel di atas, diketahui penilaian dalam aspek kelayakan isi (75\%), kebahasaan (87,5\%), penyajian $(95,83 \%)$, kegrafikan (75\%) dengan nilai akhir 87,03\%. Berdasarkan penilaian validator perangkat pembelajaran maka sumber belajar geografi berbasis weblog termasuk kategori sangat valid pada semua aspek perangkat pembelajaran (RPP).

b. Validasi Data oleh Ahli Materi (Bahan Ajar, LKPD, PPT)

Hasil analisis data validasi ahli Materi pembelajaran adalah sebagai berikut:

Tabel 4 Hasil Penilaian Ahli Materi

\begin{tabular}{|c|c|c|}
\hline Aspek & Nilai Akhir & Kriteria \\
\hline Kelayakan Isi & $88,33 \%$ & Sangat valid \\
\hline Kebahasaan & $84,72 \%$ & Sangat valid \\
\hline Penyajian & $90 \%$ & Sangat valid \\
\hline Kegrafikan & $90,27 \%$ & Sangat valid \\
\hline Jumlah & $88,27 \%$ & $\begin{array}{c}\text { Sangat } \\
\text { valid }\end{array}$ \\
\hline
\end{tabular}

Sumber : Olahan Data Primer

Berdasarkan tabel di atas, penilaian dalam aspek kelayakan isi (88,33\%), kebahasaan (84,72\%), penyajian $(90 \%)$, kegrafikan $(90,27 \%)$ dengan nilai akhir 88,27\%. Berdasarkan penilaian ahli materi maka sumber belajar geografi berbasis blog termasuk kategori sangat valid pada semua aspek materi.

c. Validasi Data Oleh Ahli Media

Hasil analisis data validasi ahli perangkat pembelajaran adalah sebagai berikut:

Tabel 5. Hasil Penilaian Ahli Media

\begin{tabular}{|l|c|c|}
\hline \multicolumn{1}{|c|}{ Aspek } & Nilai Akhir & Kriteria \\
\hline Tampilan & $89,28 \%$ & Sangat valid \\
\hline Tipografi & $85,71 \%$ & Sangat valid \\
\hline Pemograman & $95 \%$ & Sangat valid \\
\hline $\begin{array}{l}\text { Kelengkapan } \\
\text { Media }\end{array}$ & $85 \%$ & Sangat valid \\
\hline Nilai Akhir & $\mathbf{8 8 , 5 4 \%}$ & Sangat valid \\
\hline
\end{tabular}

Sumber : Olahan Data Primer

Dari tabel di atas dapat dilihat bahwa penilaian aspek tampilan 
$(89,28 \%)$, tipografi $(85,71 \%)$, pemograman (95\%), kelengkapan media (85\%) dengan nilai akhir $88,54 \%$. Berdasarkan penilaian ahli media maka sumber belajar geografi berbasis blog termasuk kategori sangat valid.

\section{Analisis Data Praktikalitas}

Hasil uji kepraktisan diperoleh dari lembar instrumen prakatikalitas yang telah diisi oleh praktisi. Hasil uji kepraktisan terdiri dari dua, yaitu uji kepraktisan oleh guru, dan uji kepraktisan oleh siswa

\section{a. Analisis Data Praktikalitas Oleh Guru Geografi}

Hasil analisis data praktikalitas oleh guru Geografi adalah sebagai berikut

Tabel 6. Hasil Penilaian Praktikalitas Oleh guru

\begin{tabular}{|l|c|c|}
\hline \multicolumn{1}{|c|}{ Aspek } & $\begin{array}{c}\text { Nilai Akhir } \\
\mathbf{P ( \% )}\end{array}$ & Kriteria \\
\hline $\begin{array}{l}\text { Kemudahan } \\
\text { Penggunaan }\end{array}$ & $97,91 \%$ & $\begin{array}{l}\text { Sangat } \\
\text { Praktis }\end{array}$ \\
\hline $\begin{array}{l}\text { Efesiensi waktu } \\
\text { pembelajaran }\end{array}$ & $100 \%$ & $\begin{array}{l}\text { Sangat } \\
\text { Praktis }\end{array}$ \\
\hline Manfaat & $100 \%$ & $\begin{array}{l}\text { Sangat } \\
\text { Praktis }\end{array}$ \\
\hline Jumlah & $\mathbf{9 9 , 1 0 \%}$ & $\begin{array}{l}\text { Sangat } \\
\text { Praktis }\end{array}$ \\
\hline
\end{tabular}

Sumber : Olahan Data Primer 2017

Dalam tabel di atas dapat diketahui bahwa penilian dalam aspek kemudahan penggunaan $(97,91 \%)$ mendapatkan kategori sangat praktis, aspek efesiensi waktu (100\%) dengan kategori sangat praktis, dan aspek manfaat $(100 \%)$ sangat praktis dengan nilai akhir 99,10\%. Berdasarkan penilaian kepraktisan oleh guru Geografi SMA Pembangunan Laboratorium UNP maka sumber belajar geografi berbasis blog termasuk kategori sangat praktis.

b. Analisis Data Kepraktisan Oleh Siswa

Hasil analisis data praktikalitas oleh siswa kelas XII IPS 1 adalah sebagai berikut:

Tabel 7 Hasil Penilaian Praktikalitas oleh siswa

\begin{tabular}{|c|c|c|}
\hline Aspek & Nilai Akhir & Kriteria \\
\hline $\begin{array}{c}\text { Kemudahan } \\
\text { penggunaan }\end{array}$ & $86,62 \%$ & $\begin{array}{c}\text { Sangat } \\
\text { praktis }\end{array}$ \\
\hline $\begin{array}{c}\text { Efisiensi } \\
\text { Waktu }\end{array}$ & $88,24 \%$ & $\begin{array}{l}\text { Sangat } \\
\text { praktis }\end{array}$ \\
\hline Manfaat & $86,76 \%$ & $\begin{array}{l}\text { Sangat } \\
\text { praktis }\end{array}$ \\
\hline Nilai Akhir & $86,76 \%$ & $\begin{array}{c}\text { Sangat } \\
\text { praktis }\end{array}$ \\
\hline
\end{tabular}

Sumber : Data Primer

Dalam tabel di atas dapat diketahui bahwa aspek kemudahan penggunaan $(86,62 \%)$ mendapatkan kategori praktis, aspek efesiensi waktu $(88,24 \%)$ dengan kategori sangat praktis, dan aspek manfaat $(86,76 \%)$ sangat praktis dengan nilai akhir $86,76 \%$. Berdasarkan penilaian kepraktisan oleh siswa maka sumber belajar geografi berbasis weblog termasuk kategori sangat praktis.

Prosedur penelitian dan pengembangan produk ini diadaptasi dari model pengembangan ASSURE dengan beberapa langkah pengembangan yang dilakukan yaitu 1) analyze learners, 2) state objective, 3) 
select methods, media dan materials, 4) utilize materials, 5) require learners participation, dan 6) evaluated and revise (dalam Pribadi, 2011:117).

Hasil validasi diperoleh dari instrumen validitas yang diisi oleh dosen sebagai ahli perangkat pembelajaran, ahli materi dan media. Hasil validasi menunjukkan bahwa sumber belajar geografi berbasis weblog sangat valid untuk digunakan sebagai sumber belajar geografi. Sumber belajar geografi berbasis weblog layak digunakan sebagai sumber belajar karena telah memiliki kelayakan pada komponen isi/materi, kebahasaan, penyajian, dan kegrafisan yang baik. Hal ini sesuai dengan teori yang dinyatakan oleh Depdiknas (2008: 28) yang menyatakan bahwa kriteria penilaian validitas sebuah sumber belajar harus mencakup komponen evaluasi mencakup analisis isi, kebahasaan, sajian dan kegrafisan. .

Hasil Praktikalitas sumber belajar geografi berbasis weblog diperoleh dari instrumen kepraktisan yang diisi oleh dua orang guru geografi dan 34 siswa kelas XII IPS 1 SMA Pembangunan Laboratorium UNP. Sumber belajar geografi berbasis weblog sanagat praktis digunakan sebagai seumber belajar karena telah memiliki kelayakan pada aspek kemudahan penggunaan, efesiensi waktu, dan manfaat. Hal ini sesuai dengan teori Sukardi (2011: 52) yang menyatakan bahwa kriteria praktikalitas dipertimbangkan melali beberapa aspek diantaranya kemudahan penggunaan, waktu yang diperlukan sebaiknya efektif dan efesien dan manfaat.

\section{PENUTUP}

Berdasarkan hasil penelitian pengembangan sumber belajar geografi berbasis weblog pada materi kelas XII SMA dapat disimpulkan bahwa:

1. Pengembangan sumber belajar berbasis weblog pada materi kelas XII SMA melalui enam tahap yaitu analisis karakter siswa/analyze learners, menetapkan tujuan pembelajaran/state objective, memilih media, metode, dan bahan ajar/select methods, media, and materials, memanfaatkan bahan ajar/utilize materials, melibatkan siswa dalam kegiatan pembelajaran/require learners and participation, evaluasi dan revisi/evaluated and revise.

2. Validasi sumber belajar Geografi berbasis weblog kelas XII berada pada kategori sangat valid. Hal ini berdasarkan penilaian ahli perangkat pembelajaran memperoleh skor akhir 87,03\%, ahli materi dengan skor akhir $88,27 \%$, dan ahli media memperoleh skor akhir 88,54\%. Berdasarkan hasil validasi deskripsi sumber belajar berbasis weblog memiliki kriteria yang sangat valid.

3. Sumber belajar Geografi berbasis weblog dinilai sangat praktis oleh guru Geografi dan siswa kelas XII IPS 1 SMA Pembangunan Laboratorium UNP. Hal ini berdasarkan penilaian oleh guru Geografi memperoleh skor akhir $99,10 \%$, dan penilaian oleh siswa memperoleh skor akhir 86,76\%. Berdasarkan analisis data pada penilitian ini, pengembangan 
sumber belajar Geografi berbasis weblog pada materi pembelajaran Geografi kelas XII SMA layak digunakan dalam pembelajaran di kelas.

Beberapa saran yang dapat diberikan berdasarkan penilitian pengembangan sumber belajar Geografi berbasis weblog pada materi pembelajaran Geografi kelas XII SMA adalah sebagai berikut

1. Pengembangan sumber belajar Geografi berbasis weblog ini bisa dilanjutkan oleh peneliti lain untuk memperdalam kajian atau pengembangan blog yang lebih optimal.

2. Sumber belajar Geografi berbasis weblog dapat digunakan secara mandiri maupun dengan bimbingan guru.

3. Pelaksanaan pembelajaran dengan sumber belajar Geografi berbasis weblog bisa bermacam macam strategi dan metode untuk mendapatkan hasil yang lebih baik.

\section{DAFTAR PUSTAKA}

Depdiknas. 2008. Panduan Pengembangan Bahan Ajar. Jakarta : Depdiknas.

Kindarto, Asdani. 2006. Tip Mudah Membuat Blog Bergaya dan Interaktif. Yogyakarta: Andi Offset.

Nofrion. 2017. EXO OLO-Task Learning Model: An Introduction To Hots-Oriented Learning Model Based On Lesson Study. Journal of
Education and Practice (Vol 8, No 28). 162-170.

Nofrion. 2017. Peningkatan Aktivitas Belajar Siswa Melalui Penerapan Metode Jumping Task Pada Pembelajaran Geografi”. Jurnal Geografi (Vol 9, No 1). 11-20.

Putra, Nusa. 2011. Research \& Development Penelitian dan Pengembangan: Suatu Pengantar. Jakarta: Rajawali Pers.

Riduwan. 2009. Belajar Mudah Penelitian Untuk Guru, Karyawan dan Peneliti Pemula. Bandung: Alfabeta.

Sumaatmadja, $\quad$ Nursid. 2001. Metodologi Pengajaran Geografi. Jakarta: Bumi Aksara.

Sukardi. 2011. Evaluasi pendidikan. Jakarta: Bumi Aksara.

Uno, B. Hamzah dan Nina Lamatenggo. 2011. Teknologi Komunikasi dan Informasi Pembelajaran. Jakarata: Bumi Aksara.

Warsita, Bambang. 2008. Teknologi Pembelajaran Landasan dan Aplikasinya. Jakarta: Rineka Cipta. 